\title{
Parto normal na gravidez de alto risco: representações sociais de primíparas
}

\section{Childbirth in high-risk pregnancy: social representations of women who had their first child}

\section{Parto natural en embazaros de alto riesgo: representaciones sociales de primíparas}

\author{
Cecilia Gardenia de Sales* \\ Hospital Agamenon Magalhães, Recife, Pernambuco, Brasil
}

\section{Telma Costa de Avelar**}

Universidade Federal de Pernambuco - UFPE, Recife, Pernambuco, Brasil

\section{Renata Lira dos Santos Aléssio***}

Universidade Federal de Pernambuco - UFPE, Recife, Pernambuco, Brasil

\begin{abstract}
RESUMO
O parto é um fenômeno natural que envolve diferentes aspectos da vida da mulher. Embora seja um evento saudável, em alguns casos, poderá ocorrer em condições clínicas desfavoráveis, como na gestação de alto risco. Considerando esta particularidade, este estudo teve como objetivo analisar as representações sociais do parto normal para mulheres que pariram nesta condição, de forma a discutir a assistência ao parto a partir de elementos por elas elencados. Participaram da pesquisa 15 puérperas, adultas. Os dados foram obtidos a partir de uma entrevista semiestruturada e os resultados analisados através da análise de conteúdo proposta por Bardin. Para melhor caracterização das participantes utilizou-se um questionário abordando questões socioeconômicas e obstétricas. Os resultados apontam que as representações do parto se estruturam a partir de concepções hegemônicas relacionadas à assistência ao parto e à maternidade. No que se refere à assistência são destacadas ambiguidades resultantes do encontro entre práticas intervencionistas e humanizadas. Espera-se contribuir com o debate no campo da assistência à saúde da mulher, ressaltando a importância das trocas interdisciplinares nas esferas teóricas e práticas. Almeja-se ainda mobilizar questionamentos acerca da assistência ao parto, ampliando, a possibilidade de superação do paradigma vigente e melhorias na assistência obstétrica.
\end{abstract}

Palavras-chave: parto, gestação, alto risco, humanização do parto.

\section{ABSTRACT}

Childbirth is a natural phenomenon that involves different aspects of women's life, although it is a healthy event, in some cases, there may be unfavorable clinical conditions, such as high-risk pregnancy. Considering this 
peculiarity, this study aimed to analyze the social representations of normal birth for women who gave birth in this condition, in order to discuss the birth assistance from elements listed by them. The participants were 15 mothers, adults. A socioeconomic questionnaire and on obstetric issues to better characterize the sample was used. The results show that the representations of childbirth are structured from hegemonic conceptions related to childbirth and maternity. With regard to assistance resulting ambiguity of the meeting between interventionists and humanized practices are highlighted. Expected to contribute to the debate in the field of health care of women, emphasizing the importance of interdisciplinary exchanges in the theoretical and practical spheres. It aims to mobilize further questions about delivery care, increasing the possibility of overcoming the current paradigm and improvements in obstetric care.

Keywords: childbirth, pregnancy, high-risk, humanization in childbirth.

\section{RESUMEN}

El parto es un fenómeno natural que envuelve diferentes aspectos de la vida de la mujer, aunque sea un evento saludable, en algunos casos, podrá ocurrir en condiciones clínicas desfavorables, como en embarazos de alto riesgo. Considerando esta particularidad, este estudio tuvo como objetivo analizar las representaciones sociales del parto natural para mujeres que parieron en esta condición, de manera a discutir la asistencia al parto a partir de elementos por ellas elencados. Participaron de la investigación 15 puérperas, adultas. Los datos fueron obtenidos a partir de una entrevista semiestructurada y los resultados analizados a través de la análisis de contenido propuesta por Bardin. Para una mejor caracterización de las participantes, se empleó un cuestionario abordando cuestiones socioeconómicas y obstétricas. Los resultados apuntan que las representaciones del parto se estructuran desde concepciones hegemónicas relacionadas a la asistencia al parto y a la maternidad. En lo que se refiere a la asistencia son destacadas ambigüedades resultantes del encuentro entre prácticas intervencionistas y humanizadas. Se espera contribuir con el debate en el campo de la asistencia a la salud de la mujer, resaltando la importancia de los cambios interdisciplinares en las esferas teóricas y prácticas. Esperase todavía movilizar cuestionamientos a cerca de la asistencia al parto, ampliando, la posibilidad de superación del paradigma vigente y mejorías en la asistencia obstétrica.

Palabras clave: parto, embarazo, alto riesgo, humanización del parto.

\section{I ntrodução}

A partir da segunda metade do século $X X$, as práticas obstétricas passaram a ser repensadas em decorrência de evidências de uma assistência marcada pela assimetria de gênero e por uma lógica produtivista (Pimentel, 2014). Denominado pela literatura de tecnocrático, este modelo caracteriza-se pelo distanciamento do parto da esfera familiar e pelo protagonismo médico associado ao uso excessivo de intervenções e tecnologias, sendo recorrente a valorização da técnica em detrimento das relações humanas (Diniz, 2005). 
Em oposição a este modelo, no Brasil, o Movimento de Humanização do Parto e Nascimento tem corroborado com a reestruturação da assistência obstétrica, visando a construção de um modelo mais humanizado. Nesse sentido, ressalta-se a importância da realização de práticas baseadas em evidências científicas: o protagonismo da mulher, a garantia de direitos, e a relevância da multidisciplinaridade na assistência (Diniz, 2005). O parto passa a ser reconhecido como um acontecimento complexo na vida da mulher e de sua família que envolve, além das questões fisiológicas, questões psíquicas, sociais e espirituais, o que indica uma ampliação do olhar sobre esse fenômeno (Rattner et al., 2014).

Embora seja significativo o crescimento dessa perspectiva, a assistência obstétrica ainda é marcada por uma forte cultura tecnicista. Ao longo do desenvolvimento da medicina o parto foi sendo paulatinamente desnaturalizado passando a ser percebido como arriscado e imprevisível, enquanto alimentava-se a crença de que a cesariana apresentava menores riscos de complicações por possibilitar um maior controle do corpo da mulher (Chacham, 2012).

Assim, as ideias de risco associadas ao parto normal e segurança do parto cirúrgico foram intensamente compartilhadas na sociedade. Atualmente o Brasil assume a liderança mundial dos índices de cesarianas, o que vem representando uma ameaça à saúde pública, uma vez que, tais procedimentos têm sido realizados de forma indiscriminada impactando negativamente na qualidade da saúde de muitas mulheres e crianças (Martins, Bezerra, Silva, \& Sousa, 2014). 0 excesso de intervenções médicas no período gestacional não se justifica, visto que a gestação não se configura como um quadro patológico, normalmente seu curso ocorre sem nenhuma intercorrência clínica. Mesmo nas situações em que há alguma ameaça à saúde e/ou a vida da mãe e/ou do feto caracterizando a gestação como de alto risco, a via de parto não é necessariamente cirúrgica e deve ser avaliada pela equipe de saúde possibilitando que a gestante e sua família participe do processo de tomada de decisão acerca do parto (BRASI L, 2012).

É fundamental a participação ativa da mulher e o olhar holístico dos profissionais de saúde no planejamento do parto. Pois, deve-se ressaltar que o ciclo gravídico-puerperal é um momento vivido de forma singular por cada mulher, tratando-se de uma fase propícia a ocorrência de alterações no comportamento e ambiguidades de sentimentos, o que pode estar relacionado, entre outros fatores, ao modo como a gestação foi vivenciada (Bortoletti, 2007). No caso da gestação de alto risco os fatores emocionais demandam maior atenção, pois o fator de risco configura-se como um estressor que desencadeia, principalmente, ansiedade e maior necessidade de adaptação (BRASIL, 2012). Essas mulheres necessitam de maior apoio da equipe de saúde por ser um grupo de maior vulnerabilidade, 
no qual o medo perpassa de maneira significativa a experiência da gestação e o parto pode ser representado como um evento angustiante (Lima et al., 2015).

Assim, a partir da Psicologia Social pretende-se contribuir com a ampliação do olhar sobre o parto na gestação de alto risco, clarificando como ele é construído no senso comum à luz da Teoria das Representações Sociais (TRS). A referida abordagem possibilita compreender as diferentes lógicas que configuram a elaboração de um objeto relevante no cotidiano das pessoas, a partir da aproximação dos saberes científicos e populares (Moscovici, 1986).

Portanto, estudar as representações sociais de um objeto, no caso deste estudo, o parto normal, significa buscar explorar o seu enraizamento na cultura e os elementos que o tornam inteligível, possibilitando a construção de referências para o direcionamento de práticas e criação de expectativas (Almeida, 2005; Moscovici, 2009; Vala, 1993). É fundamental considerar os processos de ancoragem e objetivação, enquanto o primeiro diz respeito à produção de sentido atrelada à cultura (Trindade, Santos \& Almeida, 2011), a partir do qual os novos elementos sobre o parto, por exemplo, são filtrados pelo grupo sendo aos poucos criados espaços para as novidades, o segundo ajusta as informações permitindo um consenso e facilitando a compreensão entre os pares a partir da criação de uma imagem comum ao grupo (Almeida, 2005).

As expectativas e tomadas de decisões das mulheres em relação ao parto normal, especialmente na gestação de alto risco, em que há um afastamento dos padrões de normalidade, são influenciadas por crenças relacionadas à cultura tecnicista vigente, pelos novos conceitos apresentados pelo Movimento de Humanização do Parto, bem como, pelos discursos sobre o tema compartilhados no cotidiano, fatores fundamentais para dar contornos a este objeto à medida que é socialmente construído.

Estudadas no âmbito da saúde, as representações sociais nos informam sobre as relações que mantemos com nossos corpos, mas também com o mundo e com a ordem social enquanto determinante de saúde/doença (Jodelet, 2006). Desta forma, com este estudo objetiva-se analisar as representações sociais do parto normal para primíparas que passaram pela experiência de uma gestação diagnosticada como de alto risco, de forma a discutir a assistência ao parto a partir de elementos por elas elencados. Espera-se, a partir do olhar da Psicologia Social, contribuir com o debate no campo da assistência à saúde da mulher e materno-infantil, ressaltando a importância das trocas interdisciplinares nas esferas teóricas e práticas. Almeja-se ainda mobilizar questionamentos acerca da assistência ao parto ampliando a possibilidade de superação do paradigma vigente e melhorias na assistência obstétrica. 


\section{Método}

\subsection{Participantes}

Participaram desta pesquisa15 mulheres primíparas com idade superior a 18 anos (média de idade 22 anos), usuárias do Sistema Único de Saúde (SUS), residentes da cidade do Recife e Região Metropolitana. Todas realizaram acompanhamento pré-natal, tiveram a gestação diagnosticada como de alto risco, tendo sido a maioria (11) diagnosticada com síndrome hipertensiva gestacional (SHG). Os critérios de alto risco foram delimitados de acordo com o Ministério da Saúde (BRASIL, 2012). As participantes tiveram parto normal com desfechos maternos e neonatais favoráveis. A maioria (11) afirmou preferência pelo normal desde a gestação.

\subsection{Local}

O presente estudo foi realizado no alojamento conjunto de uma maternidade referência em gestação de alto risco de um hospital universitário do estado de Pernambuco (PE).

\subsection{Instrumentos}

Foi utilizada uma entrevista semiestruturada, a partir da qual cada participante inicialmente foi convidada a falar livremente sobre a história do seu parto, em seguida foram introduzidas questões referentes as expectativas anteriores ao parto, ao conhecimento prévio sobre o assunto, as mudanças na percepção do parto após a experiência vivida e as possíveis insatisfações. A caracterização das participantes se deu a partir de um questionário abordando aspectos socioeconômicos e obstétricos.

\subsection{Procedimentos}

A coleta dos dados foi realizada no período de abril a junho de 2015 . A entrevista foi realizada em um intervalo de 24 a 72 horas após 0 parto. A maioria das mulheres participou do estudo com o neonato nos braços, alternativa sugerida pelas pesquisadoras visando evitar possíveis desconfortos ocasionados pelo afastamento da criança.

Todas as entrevistas foram gravadas com a devida autorização das entrevistadas. O número de participantes foi determinado pelo critério de saturação, assim, a realização das entrevistas foi interrompida quando as pesquisadoras observaram certa uniformidade nos discursos indicando que os principais sentidos atribuídos ao parto normal pelo grupo estudado haviam sido apreendidos (Sá, 1998). 
Para a realização da análise do conteúdo das entrevistas utilizou-se a proposta de Bardin (2009). Assim, o material das entrevistas foi transcrito e organizado em um corpus de análise, o qual foi exaustivamente lido pelas pesquisadoras na busca de unidades de sentido o que possibilitou a estruturação de três categorias nas quais temas análogos foram agrupados permitindo a elaboração das inferências deste estudo.

\subsection{Aspectos éticos}

As participantes foram orientadas quanto aos objetivos da pesquisa e o consentimento formal se deu pela assinatura do Termo de Consentimento Livre e Esclarecido (TCLE). Para garantir a confidencialidade, foram adotados nomes fictícios na apresentação de suas falas. Este estudo atende as normas da resolução 466/12 do Conselho Nacional de Saúde do Ministério da Saúde e foi aprovado pelo Comitê de Ética em Pesquisa do Centro de Ciências da Saúde da Universidade Federal de Pernambuco protocolo: CAAE: 39960214.6.0000.5208.

\section{Resultados e discussão}

O processo de análise do conteúdo das entrevistas possibilitou a organização de três categorias: "O protagonismo médico na cena do parto", "Ambiguidades em relação a dor do parto" e "Novas e velhas práticas na assistência obstétrica", as quais serão discutidas a seguir:

\subsection{O protagonismo médico na cena do parto de alto risco}

A análise dos dados aponta a experiência de sentimentos negativos tais como medo e ansiedade durante o trabalho de parto, além da atribuição do papel principal da cena do parto ao médico, enquanto assumiram um lugar secundário, como pode ser observado nas falas que seguem:

"Assim, quando falou que minha pressão tava alta, eu tive, lógico, medo né? Tanto que eu pensava: vai doer, minha pressão vai subir logo. Mas, eu tava com uma equipe de médico, né?" (Alexandra)

“... Só que para mim tava sendo muito difícil, que a minha pressão a gestação todinha ela deu super baixa, normal e quando eu comecei a entrar em trabalho de parto ela começou a subir e poderia tá dando começo de eclampsia. Aí, fiquei 
muito nervosa e com ansiedade também, e o nervosismo ele foi piorando a minha pressão..." (Taíse)

"Acho que foi a sabedoria deles né? Dos médicos, porque quando eu vim para cá eu não tava sentindo dor, mas minha pressão tava muito alta, sem sentir dor. Aí, quando eles induziram meu parto para ser normal eu senti muita dor, mas minha pressão baixou. Então, eles sabiam realmente o que tavam fazendo." (Rhayssa)

Os dados desta pesquisa corroboram a literatura sobre o tema apontando que a experiência do parto na gestação de alto risco é normalmente caracterizada por emoções negativas, predominando sentimentos de falta de controle, medo, insegurança e preocupação com a saúde e com a vida do bebê, especialmente, quando se tratam de primíparas (Costa, Figueiredo, Pacheco \& Pais, 2003).

Souza, Araújo e Costa (2013) colocam que mulheres com diagnóstico de Síndromes Hipertensivas Gestacionais (SHG), diante da gravidade dos seus quadros clínicos tendem a perceber uma maior necessidade de cuidado, nessa situação o pouco conhecimento sobre os riscos gestacionais e o medo colaboram para uma maior instabilidade emocional.

Desta forma, entende-se que a fragilidade emocional vivenciada no momento do parto pode favorecer uma maior passividade das mulheres, o que tende a se intensificar na gestação de alto risco, uma vez que o afastamento dos padrões de normalidade ajuda a legitimar a importância da medicalização, diminuindo a participação da mulher e da família no processo decisório acerca do parto como orienta o Ministério da Saúde (BRASIL, 2012).

Encontram-se evidências de que nos partos hospitalares as mulheres consideram os conhecimentos dos profissionais da saúde superiores aos seus e se percebem em uma posição subordinada, assim acabam atribuindo à equipe a função principal no momento do parto, o que caracteriza o modelo de assistência vigente (Silveira, Camargo \& Crepaldi, 2010). A percepção de que são os profissionais que possuem o legítimo saber sobre o parto é um importante elemento para a construção da representação do parto como um ato médico.

É importante ressaltar que a pouca participação ativa das mulheres é corroborada pela crença socialmente compartilhada de que o parto é algo naturalmente patológico e obrigatoriamente dependente de intervenções médicas (Diniz, 2005). Embora seja a mulher que passa pela experiência de parir, acredita-se que é o médico que "faz" o parto. Mulheres com características semelhantes às das participantes deste estudo: pardas, negras, de classes sociais menos favorecidas e atendidas nos serviços públicos de saúde, encontram maiores dificuldades para participarem das decisões no momento do parto 
(D'Orsi et al., 2014). O que lamentavelmente indica a presença de discriminação nos serviços de saúde.

Sem espaço de fala e sem reconhecerem os direitos sobre os seus corpos, as mulheres esperam não apenas a chegada da criança que gestam, mas as intervenções da equipe que determinem o sucesso do parto. Para as mulheres deste estudo, o parto é uma ação médica sobre seus corpos, representação que se ancora na hegemonia do modelo tecnocrático, e é objetivada pelas alterações fisiológicas e pela hospitalização, que normalmente se prolonga na gestação de alto risco diante da maior necessidade de cuidados clínicos. A mulher passa de protagonista a colaboradora da equipe, aguardando que as decisões sejam tomadas (Bezerra \& Cardoso, 2006). Portanto, há uma inversão de papéis que infelizmente caracteriza o modelo atual de assistência obstétrica (Portella, 2014).

\subsection{Ambiguidades em relação a dor do parto}

Nesta categoria, evidencia-se a ambiguidade vivenciada pelas mulheres em relação a dor de parir, referida como algo ruim e ao mesmo tempo necessário. Observou-se a relevância das informações sobre a dor no processo de construção da representação do parto. As parturientes chegavam ao hospital com poucas informações acerca do trabalho de parto, na maioria dos casos, a única expectativa que tinham era de que sentiram dor:

"A única coisa que eu tinha certeza era que tinha uma dor nas costas e uma dor como se fosse cólica de cima para baixo, que era ela fazendo força para sair, só! E sabia que quando ela realmente saísse as dores iam desaparecer, só isso." (Taíse)

"Eu esperava que fosse doer mais, fosse piorar as dores. Esperava que eu ia sofrer mais aqui, mas não, ocorreu tudo bem, tudo certo, graças a Deus!" (J orgiane)

É possível perceber que a imagem que essas mulheres têm do parto é construída a partir do referencial da dor, pois as informações sobre as dores do parto passam de uma geração para outra desencadeando sentimentos de medo, naturalizando o parto como algo que deve ser enfrentado para torna-se mãe. Os objetos de relevância social são objetivados no dia a dia das pessoas, nos encontros, através dos quais os saberes se afetam e se transformam, nos diálogos definindoos com base nos sentidos que são compartilhados (Jovchelovich, 2008).

Neste contexto, destaca-se o pré-natal como um momento favorável para possibilitar o diálogo e desmistificar questões sobre o parto (Bezerra \& Cardoso, 2006; Tesser, Knobel, Andrezzo \& Diniz, 2015). 
Porém, tem sido observado que as orientações sobre o parto durante o pré-natal, além de insuficientes, tendem a priorizar apenas as questões biológicas (Viellas et al., 2014).

O foco biologicista privilegiado pelos profissionais da assistência obstétrica limita o posicionamento da mulher e da família e favorece a legitimação do papel do especialista como detentor do saber. Se o parto é visto unicamente como doloroso, provavelmente as expectativas das mulheres estarão entorno do alívio desta dor, acentuando a percepção da necessidade de intervenções e a caracterização do parto como algo patológico.

Após a experiência do parto, novos elementos foram incorporados na representação do objeto, algumas avaliaram a dor de maneira diferente das informações socialmente compartilhadas. Esse é um fator de relevância, uma vez que ao tratar da construção social de um objeto deve-se considerar o jogo entre os elementos tanto de ordem social; quanto subjetiva envolvidos nesse processo (Jovchelovitch, 1995).

Portanto, são inúmeros os elementos que compõem a representação social do parto, dentre eles de forma contraditória identificou-se a dor percebida como fundamental no processo de consolidação da maternidade. Deve-se considerar que existe socialmente uma forte relação entre maternidade, amor e dor. O sacrifício materno em prol dos filhos é algo valorizado e considerado como parte da natureza feminina (Badinter, 1985). Desta forma, suportar a dor do parto seria necessário para torna-se verdadeiramente mãe, ao passo que não sentir dor pode gerar certo estranhamento, uma vez que foge à regra do sacrifício materno:

“Mas, em tudo sempre existe o amor e dor, né?! Mas, para vim o amor tem que vim a dor. Então, eu aconselho a todo mundo a ter parto normal." (Taíse)

“É essencial né? Vai ter que ter a dor de qualquer forma, se for cesárea, se for normal, vai ter que sentir o parto. E acho que você dá mais valor a vida, as coisas. Assim, tipo: as pessoas que tão junto de você, sua família, sua mãe. Você acha que vai morrer de dor, num vai morrer, mas você acha que vai. Acho que toda mãe tem que passar por essa dor pra saber o que é." (J orgiane)

De acordo com a literatura, sentir a dor do parto pode representar uma provação da condição de mulher e de mãe, assim, ao mesmo tempo a dor que amedronta, também, é esperada, necessária e valorizada como ato de amor (Almeida, Medeiros \& Souza, 2012; Bezerra \& Cardoso, 2006; Riechelmann, 2012). Essa ambiguidade tem raízes históricas relacionadas às concepções da igreja que a 
legitimava a dor como um castigo a ser pago pelo pecado original e da medicina que a considerava desnecessária estabelecendo como meta à libertação das mulheres desse castigo pelo desenvolvimento de técnicas ao longo avanço das ciências médicas (Diniz, 2005).

A ambiguidade parece ser uma característica da maternidade, o próprio corpo da mulher é socialmente percebido de forma contraditória por um lado forte e capaz e suportar a dor, por outro, acentua-se a fragilidade associada à gravidez (Almeida, Medeiros \& Souza, 2012). Fato que aponta a complexidade que envolve a assistência ao parto, logo é indispensável que as mulheres vivenciem a gestação e o trabalho de parto conhecendo as possibilidades dos seus corpos e contando com uma assistência que esteja atenta à garantia dos seus direitos.

\subsection{Novas e velhas práticas na assistência obstétrica}

Ao analisar os relatos das participantes em relação a assistência ao parto, foram observadas contradições que podem ser interpretadas como indicativas de um processo de mudança, no qual novas práticas baseadas nos princípios da humanização do parto começam a impactar o cenário da obstetrícia. As falas abaixo sinalizam a coexistência de diferentes modos de assistência:

“É não tive assistência, porque na hora que a enfermeira foi colocar a agulha na minha veia ela errou e terminou não acertando. Ela disse que eu tava nervosa e quando meu nervosismo passasse ela ia me chamar, só que em nenhum momento ela apareceu de novo." (Jorgiane)

"Aí começou induzindo o trabalho de parto, começou a colocar comprimido e eu já sem paciência, porque é um negócio muito ruim. Eu levei dezessete toques em quatro dias. Minha paciência chegava no céu. Eu odiei, pra ser sincera". (Amanda)

"Fizeram muito toque, os estudantes, desnecessário, desnecessário mesmo! E começaram... uma médica tinha feito disse: tá como um centímetro. Aí, veio o estudante: tá com o útero totalmente fechado. Aí, vinha outro e dizia: tá com um centímetro de novo-. Vinha outro dizia que eu tava com um e pouco. E ficou nessa, não sabia realmente quantos centímetros tava." (Tuíra)

É possível observar a insatisfação das mulheres em relação à assistência recebida durante o trabalho de parto (abandono, excesso de toques vaginais realizados por diversos profissionais e falta de informações) ficando evidente que em alguns momentos houve a 
falta de pactuação entre a mulher e os profissionais quanto aos procedimentos realizados. A ocorrência destas situações dolorosas faz com que o parto seja percebido como um evento degradante e que causa medo, além de afetar a crença das mulheres quanto a sua capacidade de parir (Zanardo, Uribe, Nadal, \& Habigzang, 2017).

As situações supracitadas configuram exemplos de violência obstétrica, que se caracteriza pelas negligências cometidas por profissionais da saúde durante a assistência ao parto causando dores e marcas físicas e/ou simbólicas (Muniz \& Barbosa, 2012). Esse tipo de violência ocorre nos serviços de saúde e leva a perda da autonomia da mulher. Embora este fenômeno venha sendo identificado há várias décadas em todo o mundo ainda não existe um consenso na literatura acerca de sua definição, dentre as inúmeras possibilidades de conceituação pode-se compreendê-la como uma violação dos direitos das mulheres no ciclo gravídico puerperal (Zanardo et al., 2017).

No senso comum, a violência é representada pela negligência no cuidado e desvalorização da mulher (Rodriguez, 2016). Ainda há o predomínio de uma ordem paternalista na assistência obstétrica, onde o médico assume o lugar de saber e poder sobre o corpo feminino (Leão, 2013). Fato que coloca a mulher em uma situação de vulnerabilidade, nessas situações as intervenções médicas realizadas ao longo do trabalho de parto são avaliadas pelas mulheres como indispensáveis, mesmo aquelas que são reconhecidas pela ciência como contraindicadas (Velho, Santos, Brüggemann \& Camargo, 2012).

Nesse contexto, a frequente violação de direitos no cenário da obstetrícia sinaliza uma banalização da violência, a ponto de muitas mulheres chegarem a ter dificuldades para reconhecer que sofreram violência obstétrica (Hotimisky, Aguiar \& Venturi, 2014). Lamentavelmente, a literatura tem apontado que a violência cometida por profissionais de saúde tem feito parte da assistência obstétrica de forma rotineira, sendo frequentes agressões físicas e psicológicas sofridas pelas mulheres no período perinatal (Andrade, Silva, Diniz \& Caminha, 2016; Carneiro, 2015; Tesser et al., 2015).

Estudos trazem relatos de falta de comunicação médico-paciente; abandono; violência e indiferença por parte da equipe e intervenções desnecessárias, que em muitos casos trazem danos à saúde da mãe e do bebê (Gama, Giffin, Angulo-Tuesta, Barbosa \& D'Orsi, 2009; Miranda, Bortolon, Matão \& Campos, 2008; Portella, 2014; Velho et al., 2012).

Apesar dos relatos de violência citados, também foram evidenciadas experiências positivas que sinalizam discreta e positiva mudança. A contradição chega a ponto de uma mesma mulher ter sofrido violência obstétrica e ter sido atendida de forma humanizada em diferentes momentos da hospitalização, como é o caso de Amanda: 
“.... Ela (a enfermeira) me ajudou massageou minhas costas, me deixou lá na ducha, conversava comigo, me acalmava, controlava minha respiração, não foi uma coisa desumana. Eu amei! Amei!" (Amanda)

“... Aí chegou uma doutora do plantão da noite, aí ela foi ver quantos centímetros eu tava, quando ela foi ver aí já tava vendo a cabeça do bebê. Aí chamou meu esposo, que ele assistiu o parto. Aí eu tive um parto humanizado sentada num banquinho, demorou eu nem sei quanto tempo, sei que foi rapidinho." (Luciana)

"Eu me sentia a vontade né, com eles a doutora " $V$ " que eu agradeço muito a ela, que eu num sei se eu vou ver ela ou não, que ela ficou atrás de mim me massageando, me abanando tudinho..." (Rhayssa)

Os relatos mostram que as boas práticas de assistência ao parto recomendadas pela Organização Mundial de saúde (Organização Mundial da Saúde [OMS], 1996), por exemplo, a presença de um acompanhante e as técnicas não farmacológicas de alívio da dor foram vivenciadas pelo grupo estudado, favorecendo a avaliação positiva do parto e dos cuidados recebidos. A satisfação das mulheres esteve diretamente relacionada às práticas não farmacológicas, a boa interação com a equipe, posturas menos intervencionistas, principalmente, na atuação médica, fatores que favoreceram também o estado emocional das parturientes.

Segundo a literatura, quando se trata da avaliação da experiência do parto, a satisfação das mulheres está relacionada a fatores de baixo custo e pouca tecnologia como: boa comunicação, suporte emocional, participação nos processos decisórios e privacidade ( $D^{\prime} O r s i$ et al. 2014). Sendo destacada como positiva a assistência em que os profissionais são atenciosos (Silveira et al., 2010).

Observou-se que a influência do Movimento de Humanização do Parto e Nascimento começa a fazer eco nos discursos das mulheres, isso se torna inteligível no momento em que as mulheres definem seus partos como humanizados ou não. Embora, possivelmente a maioria delas não conheça diretamente o movimento, seus ideais têm circulado na mídia pelos diversos meios de comunicação, o que tem promovido fortes influências na forma como o parto é representado (Rattner et al. 2014). Portanto, acredita-se que a partir da incorporação destes novos elementos na representação do parto criase um espaço para elaboração de novas expectativas e atitudes em relação ao parto, possibilitando tensionamentos que certamente resultarão em mudanças positivas na assistência obstétrica. 


\section{Considerações finais}

A realização deste estudo demonstrou o enraizamento dessas representações sociais do parto em aspectos culturais relacionados à hegemonia do modelo de assistência tecnocrático e a naturalização da dor como intrínseca à maternidade. Também, foi observada a introdução de novos elementos provenientes da experiência subjetiva das mulheres, bem como do contato com uma perspectiva mais humanizada de assistência ao parto.

Assim, embora o parto tenha emergido para o grupo como um evento médico no qual a mulher assume um papel secundário, surgiram também novas formas de perceber e nomear esse evento, classificando-o em humanizado ou não, e podendo se posicionar na avaliação da assistência recebida.

Ao longo da pesquisa foi possível observar que o modelo de assistência humanizado foi recebido como uma positiva novidade, dando novos contornos a percepção do parto. Desta forma, acreditase na relevância do papel do acompanhamento pré-natal na preparação da mulher/casal para o parto, sendo fundamental que elas entrem em trabalho de parto conhecendo seus direitos, possibilidades dos seus corpos e, principalmente, reconhecendo 0 parto como delas. Os profissionais da saúde de maneira interdisciplinar devem trabalhar voltados para o combate a violência obstétrica e para a promoção da autonomia das mulheres, fatores essenciais para que se consolide um novo modelo de assistência obstétrica.

Um dos limites desta pesquisa foi a realização da entrevista no interior do hospital. Uma entrevista após a alta médica, na residência das mulheres poderia fornecer elementos da relação médico-paciente que podem ter sido silenciados em função do sentimento de alívio que muitas das entrevistadas relatavam. No entanto, apesar do contexto imediatamente pós-parto e hospitalar, obtivemos informações sobre violência obstétrica realizada na instituição que merecem reflexão na construção de um sistema público de saúde que respeita e garante os direitos das mulheres e crianças.

Por fim, ressalta-se a importância da realização de pesquisas que possam vir a contribuir com a melhoria da assistência as mulheres que vivenciam gestações de alto risco, para tanto vislumbra-se o desenvolvimento de estudos que tratem da questão da violência obstétrica nesse grupo, percepção do risco ao longo do período gestacional para as mulheres e familiares e o sobre os fatores que orientam o planejamento de parto dessas mulheres. 


\section{Referências}

Almeida, A. M. (2005). A pesquisa em representações sociais: fundamentos teórico-metodológicos. In: Santos, M. F. \& Almeida, L. M. (Orgs.) Diálogos com a teoria da representação social (pp. 117-160). Recife: UFPE, Editora Universitária.

Almeida, N. A. M., Medeiros, M., \& Souza, M. R. (2012). Perspectivas de Dor do Parto Normal de Primigestas no Período Pré-natal. Texto Contexto Enfermagem, 21(4), 819-27. http://dx.doi.org/10.1590/S0104-07072012000400012

Andrade, P. O. N., Silva, J. Q. P., Diniz, C. M. M., \& Caminha, M. F. C. (2016). Fatores associados à violência obstétrica na assistência ao parto vaginal em uma maternidade de alta complexidade em Recife, Pernambuco. Revista Brasileira de Saúde Materno Infantil, 16(1), 29-37. https://dx.doi.org/10.1590/180693042016000100004

Badinter, E. (1985). Um amor conquistado, o mito do amor materno. Rio de Janeiro: Nova Fronteira.

Bardin, L. (2009). Análise de conteúdo. Lisboa: Edições 70.

Bezerra, M. G. A., \& Cardoso, M. V. L. M. L. (2006). Fatores culturais que interferem nas experiências das mulheres durante 0 trabalho de parto e parto. Revista Latino-Americana Enfermagem, 14(3), 414-21. http: //www.scielo.br/scielo.php?script=sci_arttext\&pid=S01041 $1692006000300016 \&$ Ing $=$ en\&tlng $=$ pt

Bortoletti, F. F. (2007). Psicodinâmica do ciclo gravídico puerpueral. In F. F. Bortoletti, A. F. Moron, J. B. Filho, M. U. Nakamura, R. M. Santana \& R. Mattar (Orgs), Psicologia na prática obstétrica: abordagem interdisciplinar (pp.21-31). Barueri, SP: Manole.

Brasil. Ministério da Saúde. (2012). Secretaria de Atenção à Saúde. Departamento de Ações Programáticas Estratégicas. Gestação de alto risco: manual técnico / Ministério da Saúde, Secretaria de Atenção à Saúde, Departamento de Ações Programáticas Estratégicas. 5. ed. - Brasília: Editora do Ministério da Saúde. 302 p. (Série A. Normas e Manuais Técnicos).

Carneiro, R. (2015). "Para chegar ao bojador, é preciso ir além da dor": sofrimento no parto e suas potencialidades. Sexualidade, Salude y Sociedade Revista Latinoamericana, 20, 91-112.

Chacham, A. S. (2012). Médicos, mulheres e cesárias: a construção do parto normal com "um risco" e a medicalização do parto no Brasil. In: Jacó-Viela, A. M., \& Sato, L. (Orgs) Diálogos em psicologia social (online) (pp. 420-451). Rio de Janeiro. Centro Edelstein de pesquisas sociais.

Costa, R. A., Figueiredo, B., Pacheco, A. P., \& Pais, A. (2003) Parto: expectativas, experiências, dor e satisfação. Psicologia, Saúde \& Doenças, 4(1), 47-67. 
Diniz, C. S. G. (2005). Humanização da assistência ao parto no Brasil: os muitos sentidos de um movimento. Ciência \& Saúde coletiva, 10(3), 627-637.

D'Orsi, E., Brüggemann, O. M., Diniz, C. S. G., Aguiar, J. M., Ranier, G. C. R., Torres, J. A., Angulo-Tuesta, A., Rattner, D., \& Domingues, R. M. S. M. (2014). Desigualdades sociais e satisfação das mulheres com o atendimento ao parto no Brasil: estudo nacional de base hospitalar. Cadernos de Saúde Pública, 30(1), 154-S168. https://dx.doi.org/10.1590/0102$311 \times 00087813$

Gama, A. S., Giffin, K. M., Angulo-Tuesta, A., Barbosa, G. P., \& d'Orsi, E. (2009) Representações e experiências das mulheres sobre a assistência ao parto vaginal e cesárea em maternidades pública e privada. Cadernos de Saúde Pública, 25(11), 24802488. http://dx. doi.org/10.1590/S0102-311X2009001100017

Hotimsky, S. N., Aguiar, J. M., \& Venturi, G. (2014) A violência institucional no parto em maternidades brasileiras. In: Venturi, G., \& Godinho, T. (Orgs). Mulheres brasileiras e gênero nos espaços público e privado (pp. 217-229). São Paulo: Editora Fundação Perseu Abramo: Edição Sesc.

Jodelet, D. (2006). Presença da cultura no campo da saúde. In A. M. O. Almeida, M. F. S. Santos, G. R. S. Diniz, Z. A. Trindade (Org). Violência, exclusão social e desenvolvimento humano (pp. 75-109). Brasília: Editora da UnB.

Jovchelovitch, S. (1995). Vivendo a vida com os outros: intersubjetividade, espaço público e representações sociais. In: Guareschi, P., \& Jovchelovitch, S. Textos em Representações Sociais. (pp. 63-111). Petrópolis: Vozes.

Jovchelovitch, S. (2008). Os contextos do saber: representações, comunidade e cultura. Petrópolis: Vozes.

Leão, M. R. C. (2013). Reflexões sobre o excesso de cesarianas no Brasil e a autonomia das mulheres. Ciência \& Saúde Coletiva, 18(8), 2395-2400.

Lima. M, A., Silva Filho, C. C., Tavares, V. S., Espíndola, M. M. M., Nascimento M. A. R., \& Nunes. G. F. O. (2015). Gestantes de alto risco: representações sociais do planejamento da gravidez, parto e família. Revista de Enfermagem UFPE OnLine, 9(12), 1255-63.

Martins, P. H., Bezerra, A. B., Silva, A. S., \& Sousa, I. C. (2014). Introdução: produtivismo e gestão democráticas da saúde. In Martins, P. H. In: Martins, P. H., Bezerra, A. B., Silva, A. S., \& Sousa, I. C. (Orgs.). Produtivismo na Saúde: Desafios do SUS na invenção da gestão democrática (pp. 9-26). Recife: Editora Universitária.

Miranda, D. B., Bortolon, F. C. S., Matão, M. E. L., \& Campos, P. H. F. (2008). Parto normal e cesárea: representações de mulheres 
que vivenciaram as duas experiências. Revista Eletrônica de Enfermagem, [Internet]. 10(2), 337-46.

Moscovici, S. (1986). L'ère des représentations sociales. In: Doise W. Palmonari, A. L'étude des Représentations Sociales. Paris: Delachaux \& Niestlé.

Moscovici, S. (2009). Representações sociais: investigações em psicologia social. Tradução: Pedrinho A. Guareschi. (6. Ed.) Petrópolis: Vozes.

Muniz, B. M. V., \& Barbosa, R. M. (2012). Problematizando o atendimento ao parto: cuidado ou violência? In Memorias Convención Internacional de Salud Pública. Convencção Internacional de Saúde Pública. Cuba Salud, Havana.

Organização Mundial de Saúde. (1996). Assistência ao parto normal: um guia prático. Genebra: Organização Mundial de Saúde, 54p.

Pimentel, C. (2014). A (des)colonialidade do parto: reflexões sobre o movimento de humanização do parto e do nascimento. In: Martins, P. H., Bezerra, A. B., Silva, A. S., \& Sousa, I. C. (Orgs.). Produtivismo na Saúde: Desafios do SUS na invenção da gestão democrática (pp. 99-117). Recife: Editora Universitária.

Portella, M. O. (2014). Avanços e incoerências nas políticas públicas de humanização do parto. In: Martins, P. H., Bezerra, A. B., Silva, A. S., \& Sousa, I. C. (Orgs.). Produtivismo na Saúde: Desafios do SUS na invenção da gestão democrática (pp. 119144). Recife: Editora Universitária.

Rattner, D., Jones, R. H., Diniz, S. G., Beltrão, R. S., Lopes, A. F. C., Lopes, T. C., \& Santos, S. M. (2014). Os movimentos sociais na humanização do parto e do nascimento no Brasil In: Brasil. Ministério da Saúde. (2014). Humanização do parto e do nascimento / Ministério da Saúde (pp. 109-132). Brasília: Universidade Estadual do Ceará - Ministério da Saúde

Riechelmann, J. C. (2012). Abordagem psicossomática da mulher dolorida: a interface entre objetividade e subjetividade das dores de ser mulher. In: Angerami - Camon (Org.). Psicossomática e psicologia da dor (pp. 129-151). São Paulo: Pioneira Thomson Learnig.

Rodriguez, M. J. H. (2016) Representações sociais de mulheres acerca da violência obstétrica institucional no trabalho de parto e parto (Tese de Doutorado). Universidade Federal de Santa Catarina, Florianópolis.

Sá, C P. (1998). A construção do objeto de pesquisa em representações sociais. Rio de J aneiro: EdUERJ .

Silveira, S. C., Camargo, B. V., \& Crepaldi, M. A. (2010) Assistência ao parto na maternidade: representações sociais de mulheres assistidas e profissionais de saúde. Psicologia. Reflexão. Crítica, 
23(1), $\quad 01-10$.

http://dx.doi.org/10.1590/S0102-

79722010000100002

Souza, N. L., Araujo, A. C. P. F., \& Costa, I. C. C. (2013). Representações sociais de puérperas sobre as síndromes hipertensivas da gravidez e nascimento prematuro. Revista Latino-Americana de Enfermagem, 21(3). http://www.scielo.br/pdf/rlae/v21n3/pt_0104-1169-rlae-21-030726.pdf

Tesser, C. D., Knobel, R., Andrezzo, H. F. A., \& Diniz, S. D. (2015). Violência obstétrica e prevenção quaternária: o que é e o que fazer. Revista Brasileira de Medicina Família e Comunidade, 10(35), 1-12. http://dx. doi.org/10.5712/rbmfc

Trindade, Z. A., Santos, M. S. S. \& Almeida, A. M. O. (2011). Ancoragem: notas sobre consensos e dissensos. In: Almeida, A. M. O., Santos, M. F. S. \& Trindade, Z. A. (Org.). Teoria das Representações Sociais 50 anos (pp. 101-194). Brasília: Technopolitik.

Vala, J. (1993). Representações sociais para uma psicologia social do pensamento social. In: Vala, J., \& Monteiro, M. B. (Orgs.). Psicologia Social (pp. 353-384). Lisboa: Fundação Calouste Gulbenkian.

Velho, M. B., Santos, E. K. A., Brüggemann, O. M., \& Camargo, B. V. (2012). Vivência do parto normal ou cesáreo: revisão integrativa sobre a percepção de mulheres. Texto contexto enfermagem, 21(2), 458-66.

Viellas, E. F., Domingues, R. M. S. M., Bastos, D. M. A. B., Gama, S. G. N., Theme Filha, M. M., Costa, J. V., Bastos, M. H., \& Leal, M. C. (2014). Assistência pré-natal no Brasil. Cadernos de Saúde Pública, 30(suppl.1), S85-S100. https: //dx.doi.org/10.1590/0102-311X00126013

Zanardo, G. L. P., Uribe, M. C., Nadal, A. H. R., \& Habigzang, L. F. (2017). Violência obstétrica no brasil: uma revisão narrativa. Psicologia \& Sociedade, 29, e155043. Epub July 10, 2017. https://dx.doi.org/10.1590/1807-0310/2017v29155043

\section{Endereço para correspondência \\ Cecilia Gardenia de Sales}

Hospital Agamenon Magalhaes

Secretaria Estadual de Saúde do Estado de Pernambuco - SES / PE

Rua Costa Gomes, 202 Apt 204, Edifício Monte Passy, Madalena, CEP 50710-510, Recife - PE, Brasil

Endereço eletrônico: ceciliasales6@gmail.com

Telma Costa de Avelar

Universidade Federal de Pernambuco

Centro de Filosofia e Ciências Humanas - Departamento de Psicologia

Avenida Professor Moraes Rego, s/n, Cidade Universitária, CEP 50670-420, Recife PE, Brasil

Endereço eletrônico: avelar.telma@gmail.com 


\section{Renata Lira dos Santos Aléssio}

Universidade Federal de Pernambuco

Centro de Filosofia e Ciências Humanas - Departamento de Psicologia

Avenida Professor Moraes Rego, s/n, Cidade Universitária, CEP 50670-420, Recife PE, Brasil

Endereço eletrônico: renatalir@gmail.com

Recebido em: 05/03/2016

Reformulado em: 08/02/2017

Aceito em: 08/08/2017

\section{Notas}

* Mestre em Psicologia pela Universidade Federal de Pernambuco.

** Mestre em Psicologia Cognitiva pela Universidade Federal de Pernambuco, Brasil. Docente do departamento de Psicologia da Universidade Federal de Pernambuco.

*** Doutora em Psicologia Social pela Université D’Aix-Marseille.

Este artigo de revista Estudos e Pesquisas em Psicologia é licenciado sob uma Licença Creative Commons Atribuição-Não Comercial 3.0 Não Adaptada. 